\title{
Editorial: Adapting core features of learning development: skills and writing support
}

\author{
Gita Sedghi \\ University of Liverpool
}

One of the core features of learning developers' work is to support students to develop their academic skills and reach their fullest academic potential. These skills include academic writing and reading, presentation skills, time management, independent learning and critical thinking. In addition to this hands-on academic support, learning developers create resources to enhance learning and teaching, and provide opportunities for independent learning. Unsurprisingly, the disruption wrought by Covid-19 presented LD colleagues across UK institutions and globally with a range of challenges when designing their teaching provision for studying online.

Although many effective approaches to learning that are often used in online educational spaces were already available at the start of this emergency pivot (e.g. flipped classroom), the authors in this section quickly found that not everything could be easily adapted, let alone delivered as before. Striking the right balance between synchronous and asynchronous delivery, maintaining student engagement, shifting pedagogic approaches, and rethinking the existing forms of delivering academic support were the key challenges that had to be addressed by these practitioners.

Learning developers essentially had to reconsider their role as academic advisors, providers of one-to-one tutorials, instructors in writing, and facilitators of cutting edge learning environments in the face of multiple difficulties brought about by unfamiliar modalities. Their efforts reflected on here demonstrate that conversations, interactions with others, and unencumbered opportunities to exchange ideas are essential in higher education, but online settings can undermine these ideal conditions. As Grondin et al. (2019) point out, communication difficulties can be exacerbated in online learning because of poor connectivity and less noticeable non-verbal language. Many issues that do not occur as much in in-person teaching arise in online contexts, including digital poverty, distractions from children at home, and interruptions from other online participants. 
The following Compendium pieces bring together the initiatives and strategies the educators reflecting here used to overcome the challenges posed by the online pivot. A digital tutoring hub was created to support students who missed interactions and corridor conversations, and Active Listening and Oral Paraphrasing techniques were used in online communication. Virtual spaces on various platforms allowed peer support mechanisms to be developed, and e-portfolios provided a focus for students to plan their own development and work with their tutor and tutor group to identify goals and achieve them. Online academic speaking clubs were established to mitigate the international students' difficulties, with the sessions boosting students' confidence in speaking, discussing ideas, improving participation and making friends. As learning developers across the globe reconsidered their approaches to teaching and to formal and informal learning spaces, they also humanised their students' learning experience.

The authors have made several recommendations to deal with unknown situations and inadequate understanding of online learning in an emergency setting. For example, they advocate using YouTube to improve students' digital literacies, simple study skills and engagement. Online videos offer students the flexibility to access support any time, any day. Transitioning to a webinar-based delivery model, supplemented with web resources that are also shared with instructors, is another initiative to make effective use of available technologies with student engagement features, and to leverage these tools as mediating factors for fostering student engagement in learning.

\section{References:}

Grondin, F., Lomanowska, A. M. and Jackson, P. L. (2019) 'Empathy in computermediated interactions: a conceptual framework for research and clinical practice', Clinical Psychology: Science and Practice, 26(4). https://doi.org/10.1111/cpsp.12298. 